\title{
Chelidonium majus-Induced Acute Hepatitis
}

\author{
Sung Gyu Im, Sun Hong Yoo, Dong Ok Jeon, Hyo Jin Cho, Jin Young Choi, Soya Paik ${ }^{1}$, Young Min Park \\ Hepatology Center, ${ }^{1}$ Department of Pathology, Bundang Jesaeng General Hospital, Seongnam, Korea
}

\begin{abstract}
The use of traditional folk remedies is increasing throughout Asia. Chelidonium majus, a popular herbal remedy, is used to treat abdominal pain caused by various gastrointestinal disorders, including gastric ulcer, gastritis, and biliary tract disease, because of its morphine-like effect. We encountered a 62-year-old woman with acute hepatitis, in which $C$. majus was suspected to be the etiological factor. The patient had taken high dose of $C$. majus extract for the preceding 60 days. The clinical context and the temporal association between the start of the herbal medicine treatment and her liver injury allowed us to attribute a causative role to C. majus. The diagnosis was confirmed by liver biopsy and the Council for International Organizations of Medical Sciences/Roussel Uclaf Causality Assessment Method (CIOMS/RUCAM) scale. After C. majus was discontinued, the liver function was restored to normal. In conclusion, because the use of phytotherapy is increasing, we wish to raise awareness of the potential adverse effects of C. majus. (Ewha Med J 2014;37(1):60-63)
\end{abstract}

Received August 20, 2013,

Accepted September 10, 2013

\section{Corresponding author}

Sun Hong Yoo

Hepatology Center, Bundang Jesaeng General

Hospital, 20, Seohyeon-ro 180 beon-gil,

Bundang-gu, Seongnam 463-774, Korea

Tel: 82-31-779-5065, Fax: 82-31-779-0164

E-mail: hepayoo@dmc.or.kr

Key Words

Drug-induced liver injury; Chelidonium majus; the CIOMS/RUCAM scale; Biopsy

\section{Introduction}

Medicinal herbs, defined as preparations concocted by an unauthorized layperson [1], are used widely in Asian countries because they are easily available and are believed to be harmless. Despite this belief, hepatitis, and even fulminant hepatitis, associated with medicinal herbs has been reported. According to previous reports, drug-induced liver injury accounts for 2 40\% of all liver injury [24]. Chelidonium majus (C. majus), a widely used medicinal herb, is taken for its choleretic and spasmolytic properties by patients with biliary disorders, dyspepsia, and irritable bowel syndrome [5]. When the fresh latex of $C$. majus is ingested, severe irritation of the oral mucosa, throat, stomach, and gut can occur. When the plant is applied to the skin, it can cause irritation, blisters, and allergic contact dermatitis [6]. Although its mechanism remains unclear, $C$. majus could lead to hepatotoxicity presenting as acute cholestatic hepatitis $[7,8]$. Here, we describe a case of acute C. majus-induced hepatitis.

\section{Case}

A 62-year-old woman was admitted to our hospital with symptoms of anorexia, dyspepsia, nausea, abdominal discomfort, and jaundice of 14 days' duration. Her medical history included no hepatic disease or metabolic disease, such as diabetes mellitus or hypertension. She reported no alcohol consumption, smoking, or hepatotoxic drug abuse, including nonsteroidal anti-inflammatory drugs. The patient had taken $400 \mathrm{~mL}$ of $C$. majus solution daily for the preceding 60 days for knee arthralgia. When she was hospitalized, her use of $C$. majus was discontinued. On physical examination, she was alert and well-oriented, but with icteric sclera and a palpable liver on inspiration. On admission, her laboratory results were: total bilirubin $1.95 \mathrm{mg} / \mathrm{dL}$ (normal range, 0.2 to $1.4 \mathrm{mg} / \mathrm{dL}$ ), alanine aminotransferase $327 \mathrm{IU} / \mathrm{L}$ (normal range, 0 to $40 \mathrm{IU} / \mathrm{L}$ ), aspartate aminotransferase $711 \mathrm{IU} / \mathrm{L}$ (normal range, 0 to $40 \mathrm{IU} /$ L), alkaline phosphatase $571 \mathrm{IU} / \mathrm{L}$ (normal range, 105 to $357 \mathrm{IU} /$ L), $\gamma$-glutamyl transpeptidase (GTP) 955 IU/L (normal range, 9 to $42 \mathrm{IU} / \mathrm{L}$ ), serum albumin $3.9 \mathrm{~g} / \mathrm{dL}$ (normal range, 3.3 to $5.2 \mathrm{~g} /$ $\mathrm{dL}$ ), creatinine $0.79 \mathrm{mg} / \mathrm{dL}$ (normal range, 0.8 to $1.5 \mathrm{mg} / \mathrm{dL}$ ), and 
sodium $140 \mathrm{mmol} / \mathrm{L}$ (normal range, 135 to $145 \mathrm{mmol} / \mathrm{L}$ ). Her international normalized ratio was 1.02 (normal range, 0.8 to 1.2). Her blood cell counts and other common blood tests, including electrolytes, were normal. The results of serological tests, including for HBsAg, HBeAg, anti-HBe, anti-HBcIgM, anti-HBcIgG, antiHCV, HCV-RNA, and anti-HAV-IgM, were negative. Serological tests for autoimmune disorders, including anti-nuclear antibodies, anti-smooth muscle antibodies, liver-kidney-microsomal antibodies, anti-mitochondrial antibodies, and anti-neutrophil cytoplasmic antibodies, were negative. Her serum ceruloplasmin, urinary copper excretion, and ferritin were also normal. Abdominal ultrasound showed a mildly fatty liver. The patient underwent a percutaneous liver biopsy. Pathological analysis of the liver biopsy revealed moderate lobular hepatitis with hepatocyte ballooning degeneration and numerous acidophil bodies. The portal area also showed mild inflammation consisting of lymphocytes and eosinophils (Fig. 1). The patient's $\mathrm{R}$ value was 5.11, indicating hepatocellular drug-induced liver injury [9]. The Council for International Organizations of Medical Sciences/Roussel Uclaf Causality Assessment Method (CIOMS/RUCAM) scale was applied, revealing highly probable drug-induced liver injury (Table 1) [10]. The management of acute hepatitis focused on monitoring the patient's liver function and
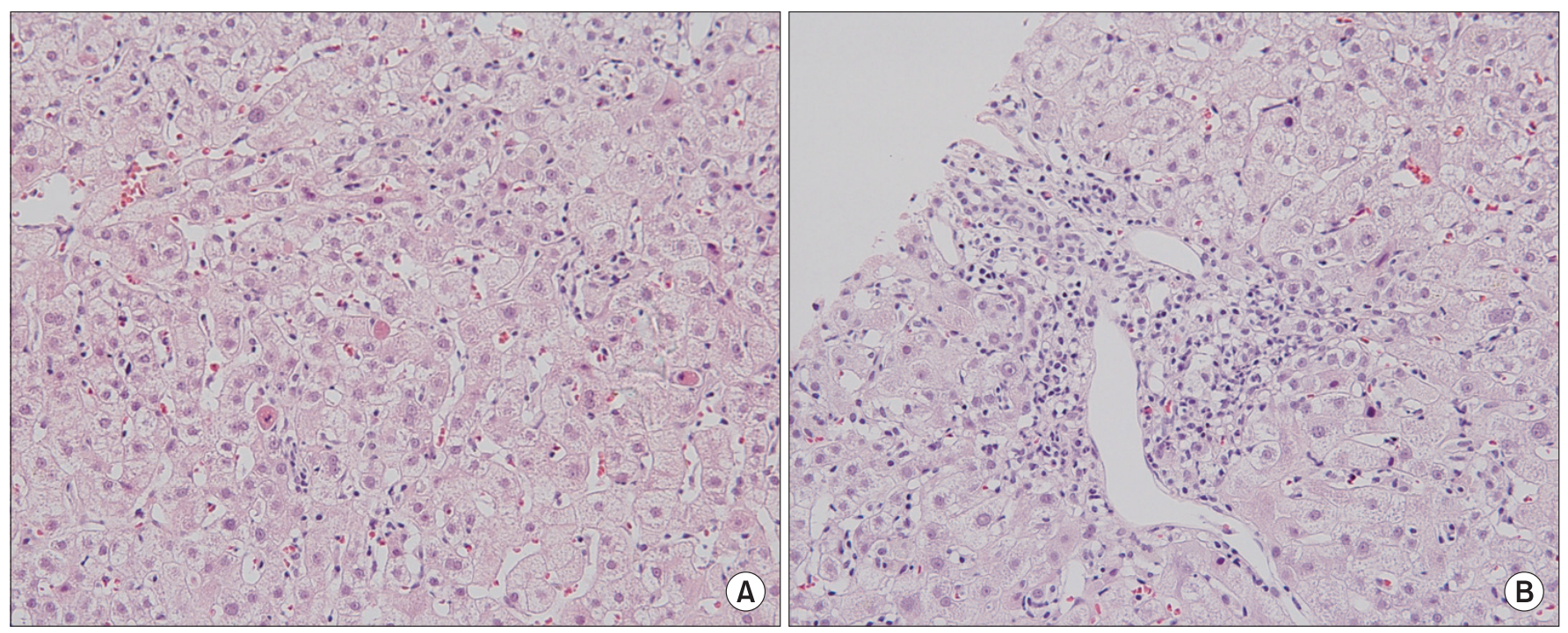

Fig. 1. Histologic findings. (A) Histologic findings of liver reveals lobular inflammation showing frequent acidophil necrosis and hepatocyte ballooning $\left(H \& E_{1} \times 200\right)$. (B) Histologic findings of liver reveals mild portal lymphocytic and eosinophilic inflammatory cell infiltration (H\&E, $\left.\times 200\right)$.

Table 1. The Council for International Organizations of Medical Sciences/Roussel Uclaf Causality Assessment Method (CIOMS/RUCAM) scale of the patient [10]

\begin{tabular}{|c|c|c|}
\hline Type of liver injury & Hepatocellular & Points \\
\hline Time of onset of the event & First exposure & \\
\hline Time from drug intake until reaction onset & 5 to 90 days & +2 \\
\hline Time from drug withdrawal until reaction onset & $\leq 15$ days & +1 \\
\hline Risk factors & $\begin{array}{l}\text { No alcohol } \\
\text { Age } \geq 55 \text { years }\end{array}$ & $\begin{array}{l}+0 \\
+1\end{array}$ \\
\hline Course of the reaction & $>50 \%$ improvement 30 days & +2 \\
\hline Concomitant therapy & None & +0 \\
\hline Exclusion of nondrug-related causes & Rule out & +2 \\
\hline Previous information on hepatotoxicity & Reaction published but unlabeled & +1 \\
\hline Response to re-administration & Not done & +0 \\
\hline Score analysis & Highly probable & +9 \\
\hline
\end{tabular}




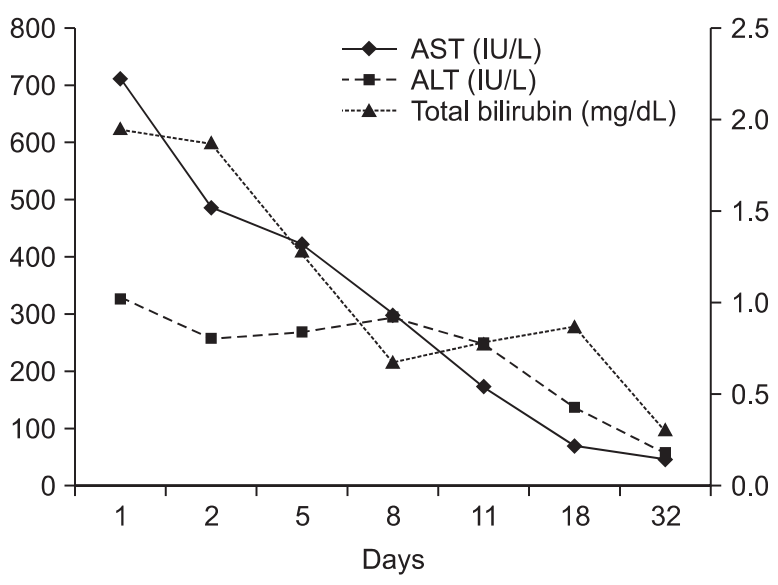

Fig. 2. Hepatic enzymes (AST, ALT) and total bilirubin behavior. AST, aspartate aminotransferase; ALT, alanine aminotransferase.

her symptoms. In the four days after her admission, the patient's aminotransferase, total bilirubin, alkaline phosphatase, and $\gamma$-GTP levels and her symptoms had improved (Fig. 2). The patient was discharged on day 12, with plans for outpatient follow-up, and remained symptom free at a visit to the outpatient clinic one month later.

\section{Discussion}

Chelidonium majus L., also called the greater celandine, swallowwort, or bag-gul-chae in Korean, belongs to the poppy family Papaveraceae [11]. It is an important plant in Western phytotherapy and traditional Chinese medicine. C. majus is used to treat cholestatic hepatitis, gastric ulcer, irritable bowel syndrome, oral infections, pain induced by biliary disease, skin eruptions, quadriplegia, and tuberculosis in Western phytotherapy. The juice of the plant is a known herbal medicine, used to remove warts and skin ulcers $[12,13]$. In traditional Chinese medicine, C. majus is used to treat blood stasis, reduce the pain induced by gastric ulcer, promote dieresis, treat cholestatic hepatitis, and treat abdominal pain induced by biliary disease $[13,14]$. Although C. majus has important therapeutic activities, its fresh latex and herbal preparations can have several toxic effects, such as severe irritation of the oral mucosa, throat, stomach and gut, allergic contact dermatitis, and acute cholestatic hepatitis. In Korea, C. majus is used as a medicinal herb to relieve the pain induced by gastric ulcer or biliary disease. Nevertheless, the hepatotoxicity of C. majus has never been reported in Korea.

It is difficult to establish a causal relationship between a medicinal herb and hepatotoxicity because specific diagnostic methods are usually unavailable [15]. For this reason and because there is a lack of reliable appropriate biomarkers, several diagnostic scoring systems have been developed for the diagnosis of drug-induced liver injury, such as the CIOMS/RUCAM scale, the Naranjo probability scale, and the Maria and Victorino clinical scale. The CIOMS/ RUCAM scale, which is the most commonly used scoring system, is based on seven domains: chronology, risk factors, concomitant drug use, search for other etiologies, existing information on the drug's hepatotoxic potential, and response to rechallenge. This scoring system also categorizes the degree of suspicion as highly probable (score $>8$ ), probable (score $6 \sim 8$ ), possible (score 3 5), unlikely (score 1 2), or excluded (score 0) [16]. The CIOMS/RUCAM scale has shown $86 \%$ sensitivity, $89 \%$ specificity, $93 \%$ positive predictive value, and $78 \%$ negative predictive value when a cutoff point of 5 is used [17]. In most previously reported cases of $C$. majus hepatotoxicity, when the CIOMS/RUCAM scale was applied, causality levels were low, rated as probable, possible, or excluded [18]. In the present case, the causal role of $C$. majus was established because all other common causes of acute hepatitis were excluded, and the CIOMS/RUCAM scale scored this etiology as highly probable. Moreover, the histology was compatible with drug-induced liver injury.

The pathogenetic mechanism of $C$. majus hepatotoxicity has not yet been determined. An idiosyncratic reaction is considered the most likely mechanism of $C$. majus hepatotoxicity because its effect is not dose dependent and the latency period is variable [7,11]. More than 20 alkaloids of C. majus have biological activity, including chelidonine, sanguinarine, berberine, coptisine, and chelerythrine, all of which are potentially toxic either alone or in combination [7].

The use of medicinal herbs for various medical conditions is increasing, in the belief that they are harmless. However, hepatotoxicities such as acute hepatitis, liver cirrhosis, and even fulminant hepatitis have been attributed to medicinal herbs in several reports. C. majus is a medicinal herb commonly used in Europe and Asia to treat the pain induced by gastric ulcer or biliary disease. Here, we have described the case of $C$. majus-induced herbal hepatotoxicity, presenting as hepatocellular-type hepatitis.

\section{References}

1. Suk KT, Kim DJ. Drug-induced liver injury: present and future. Clin Mol Hepatol 2012;18:249-257.

2. Kang SH, Kim JI, Jeong KH, Ko KH, Ko PG, Hwang SW, et al. Clinical characteristics of 159 cases of acute toxic hepatitis. Korean J 
Hepatol 2008;14:483-492.

3. Ostapowicz G, Fontana RJ, Schiodt FV, Larson A, Davern TJ, Han SH, et al. Results of a prospective study of acute liver failure at 17 tertiary care centers in the United States. Ann Intern Med 2002;137:947-954.

4. Suk KT, Kim DJ, Kim CH, Park SH, Yoon JH, Kim YS, et al. A prospective nationwide study of drug-induced liver injury in Korea. Am J Gastroenterol 2012;107:1380-1387.

5. Pieroni A, Dibra B, Grishaj G, Grishaj I, Gjon Maçai S. Traditional phytotherapy of the Albanians of Lepushe, Northern Albanian Alps. Fitoterapia 2005;76:379-399.

6. Etxenagusia MA, Anda M, Gonzalez-Mahave I, Fernandez E, Fernandez de Corres L. Contact dermatitis from Chelidonium majus (greater celandine). Contact Dermatitis 2000;43:47.

7. Benninger J, Schneider HT, Schuppan D, Kirchner T, Hahn EG. Acute hepatitis induced by greater celandine (Chelidonium majus). Gastroenterology 1999;117:1234-1237.

8. Stickel F, Pöschl G, Seitz HK, Waldherr R, Hahn EG, Schuppan D. Acute hepatitis induced by greater celandine (Chelidonium majus). Scand J Gastroenterol 2003;38:565-568.

9. Watkins PB, Seeff LB. Drug-induced liver injury: summary of a single topic clinical research conference. Hepatology 2006;43:618-631.

10. Danan G, Benichou C. Causality assessment of adverse reactions to drugs--I. A novel method based on the conclusions of international consensus meetings: application to drug-induced liver injuries. J Clin Epidemiol 1993;46:1323-1330.

11. Boyer T, Manns MP, Sanyal AJ. Hepatotoxicity of herbal prepara- tions. In: Boyer TD, Manns MP, Sanyal AJ, editors. Zakim and Boyer's hepatology: a textbook of liver disease. 6 th ed. Philadelphia, PA: Elsevier Saunders; 2011. p.462-475.

12. Colombo ML, Bosisio E. Pharmacological activities of Chelidonium majus L. (Papaveraceae). Pharmacol Res 1996;33:127-134.

13. Gilca M, Gaman L, Panait E, Stoian I, Atanasiu V. Chelidonium majus: an integrative review: traditional knowledge versus modern findings. Forsch Komplementmed 2010;17:241-248.

14. Jeng JH, Wu HL, Lin BR, Lan WH, Chang HH, Ho YS, et al. Antiplatelet effect of sanguinarine is correlated to calcium mobilization, thromboxane and cAMP production. Atherosclerosis 2007;191:250-258.

15. Andrade RJ, Robles M, Fernandez-Castaner A, Lopez-Ortega S, Lopez-Vega MC, Lucena MI. Assessment of drug-induced hepatotoxicity in clinical practice: a challenge for gastroenterologists. World J Gastroenterol 2007;13:329-340.

16. Danan G, Benichou C. Causality assessment of adverse reactions to drugs I. A novel method based on the conclusions of international consensus meetings: application to drug-induced liver injuries. J Clin Epidemiol 1993;46:1323-1330.

17. Benichou C, Danan G, Flahault A. Causality assessment of adverse reactions to drugs II. An original model for validation of drug causality assessment methods: case reports with positive rechallenge. J Clin Epidemiol 1993;46:1331-1336.

18. Teschke R, Glass X, Schulze J, Eickhoff A. Suspected Greater Celandine hepatotoxicity: liver-specific causality evaluation of published case reports from Europe. Eur J Gastroenterol Hepatol 2012;24:270-280. 